\title{
An Escalating Dose "Binge" Model of Amphetamine Psychosis: Behavioral and Neurochemical Characteristics
}

\author{
David S. Segal and Ronald Kuczenski \\ Psychiatry Department, University of California, San Diego, School of Medicine, La Jolla, California 92093
}

\begin{abstract}
Stimulant-induced psychosis is most frequently associated with a chronic, high-dose, multiple daily ("binge") exposure pattern of stimulant abuse. To simulate these conditions, rats were exposed to escalating doses of amphetamine (Escalating Dose phase, $1.0-8.0 \mathrm{mg} / \mathrm{kg}$ ) before multiple daily injections of relatively high doses of the drug (Run phase, $8.0 \mathrm{mg} / \mathrm{kg} / 2 \mathrm{hr} \times$ 4 injections). Behavior was monitored continuously during the course of these treatments as well as during subsequent amphetamine challenges at various times after discontinuation of drug treatment. With the Escalating Dose-Run pattern of administration, a unique behavioral profile emerged in which tolerance occurred to the amount of time spent engaged in con-
\end{abstract}

tinuous focused stereotypy simultaneous with a profound increase in ambulatory activity that appeared agitated and disorganized. Parallel in vivo microdialysis studies showed progressively declining extracellular dopamine and serotonin responses, both within and between successive runs, whereas the norepinephrine response remained relatively unaltered. We propose that this model more closely resembles clinical manifestations of amphetamine psychosis and that the alterations may reflect a shift in the relative activation of mesolimbic and nigro-striatal dopamine pathways.

Key words: amphetamine; stereotypy; locomotion; binge; psychosis; microdialysis; dopamine; norepinephrine; serotonin
Animal studies have shown that repeated administration of amphetamine-like stimulants results in an altered response profile, one prominent feature of which is behavioral sensitization (for review, see Segal et al., 1981, Robinson and Becker, 1986; Kalivas et al., 1993; Segal and Kuczenski, 1994). It has been suggested that this progressive enhancement in responsiveness may be implicated in the various forms of psychopathology observed with stimulant abuse (Segal and Mandell, 1974; Post and Kopanda, 1976; Kilbey and Ellinwood, 1977; Segal and Janowsky, 1978; Segal and Schuckit, 1983; Segal and Geyer, 1985) and, in fact, recent clinical findings are consistent with a role for sensitization in the appearance of stimulant-induced paranoid psychosis (Brady et al., 1991; Satel et al., 1991; Angrist, 1994b; Gawin and Khalsa, 1996). However, because many factors influence stimulant response characteristics, it would be especially important to simulate the human abuse patterns most frequently associated with the induction of psychosis to accurately assess the possible mechanisms responsible for these effects.

Several issues are important in this regard. For one, an appropriate animal behavior model should include exposure to gradually escalating doses of the stimulant, because this is a common usage pattern of high-dose stimulant abusers (Gawin, 1991; Angrist, 1994b; Gawin and Khalsa, 1996). Escalating dose regimens in animals have been used primarily to examine the response to

Received Aug. 6, 1996; revised Dec. 4, 1996; accepted Dec. 6, 1996.

This work was supported by U.S. Public Health Service Grants DA-01568 and DA-04157 and Public Health Service Research Scientist Award MH-70183 to D.S.S We wish to thank Drs. Arthur Cho and William Melega for analysis of tissue levels of amphetamine. We wish to express our appreciation to Brad Hirakawa and S. McCunney for assistance in executing the experimental protocol, Molly Roznoski and Joseph Higgins for their skills in performing the dialysis experiments, Julie Segal and Stefan Grafstein for their expert rating of videotapes, and Pat Hermann for her efforts in preparing the manuscript.

Correspondence should be addressed to Dr. David S. Segal, Psychiatry Department (0603), UCSD School of Medicine, 9500 Gilman Drive, La Jolla, CA 92093.

Copyright (C) 1997 Society for Neuroscience $0270-6474 / 97 / 172551-16 \$ 05.00 / 0$ lower challenge doses of the stimulant (Robinson et al., 1988; Paulson et al., 1991). Results obtained from these studies indicate that the responses to challenge are comparable after escalating dose pretreatment and single daily injections, especially after relatively long withdrawal periods (Paulson and Robinson, 1995). Importantly, however, there are no reports of systematic analyses of the behavioral response during the escalating dose regimen.

Furthermore, as tolerance develops to the sympathomimetic effects of the stimulants, abusers are able to survive higher doses (Fischman and Schuster, 1974, 1977; Schuster and Fischman, 1975; Schmidt et al., 1985b; Angrist, 1994b) and thus increase both the dose and frequency of administration, presumably to achieve and maintain high levels of the euphoria produced by these drugs (Angrist, 1987, 1994b; Gawin and Khalsa, 1996). Thus, escalating doses frequently lead to a high dose binge pattern of administration, and prevailing evidence suggests that psychosis is most frequently associated with this pattern of stimulant abuse (Davis and Schlemmer, 1980; Angrist, 1994b; Gawin and Khalsa, 1996). Therefore, characterization of the behavioral and neurochemical responses during multiple binges may provide the greatest potential for understanding the neurochemical mechanisms and behavioral processes most frequently associated with craving and compulsive use as well as with the induction of psychosis (Griffith et al., 1972; Kramer, 1972; Schmidt et al., 1985b; Angrist, 1987, 1994b; Gawin, 1991; Unterwald et al., 1994; Gawin and Khalsa, 1996). To simulate these conditions, we have undertaken a series of studies in which rats were exposed to gradually escalating doses of $d$-amphetamine (AMPH) before multiple daily administrations of relatively high doses of the drug. Animals monitored continuously throughout the course of these treatments developed a unique pattern of behavior that emerged through the course of multiple runs. These effects and corresponding changes in extracellular monoamines may provide new insight into the pathophysiology of stimulant-induced psychosis. 


\begin{tabular}{|c|c|c|c|}
\hline \multirow[b]{2}{*}{ Day } & \multicolumn{3}{|l|}{ Time } \\
\hline & 8 A.M. & 2 P.M. & 8 P.M. \\
\hline 1 & $1^{a}$ & 2 & 3 \\
\hline 2 & 3 & 4 & 5 \\
\hline 3 & 5 & 6 & 7 \\
\hline 4 & 7 & 8 & \\
\hline
\end{tabular}

${ }^{a} \mathrm{mg} / \mathrm{kg}$.

\section{MATERIALS AND METHODS}

Subjects. Male Sprague Dawley rats, weighing 325-350 gm at the beginning of drug treatment, were housed for at least 1 week before experimental manipulation in groups of 2 or 3 in wire mesh cages in a temperature- and humidity-controlled room, maintained on a 14:10 hr light/dark cycle (5:00 A.M. to 7:00 P.M.). Animals were obtained from Simonsen Labs (Gilroy, CA).

Apparatus. Behavior was monitored in custom-designed activity chambers (see Segal and Kuczenski, 1987). Briefly, each of the chambers was located in a sound attenuated cabinet maintained on a 14/10 hr light/dark cycle with constant temperature and humidity. Food and water were available ad libitum. Each chamber consisted of two compartments: an activity/exploratory compartment $(30 \times 20 \times 38 \mathrm{~cm})$ and a smaller "home" compartment $(14 \times 14 \times 10 \mathrm{~cm})$ in which food and water were located. Movements of the animal between quadrants within the activity/ exploratory compartment (crossovers) and rearings against the wall, as well as eating and drinking and other vertical (e.g., contact with a hanging stimulus) and horizontal movements (e.g., intercompartment crossings), were monitored continuously by computer. In addition to the computermonitored behaviors, representative animals, chosen at random from each group $(n=5-7)$ were videotaped simultaneously for $60 \mathrm{sec}$ at successive $5 \mathrm{~min}$ intervals for up to $8 \mathrm{hr}$ to assess the qualitative features of the response during both the stereotypy and the poststereotypy phases. Raters who were unaware of the specific experimental conditions subsequently rated the videotapes on the basis of behavior ethograms and rating procedures established previously (Segal and Kuczenski, 1987). Stereotypy was assessed as the percentage of the observation interval during which the animal displayed each specific behavior. The appearance of other atypical responses or behavior patterns, undetectable by our automated methods, were noted by the rater after each sampling interval. Because of the magnitude of the experiment, it was not possible to videotape sample behaviors from all animals; therefore, sets of rats from the most relevant groups were randomly selected for observational ratings.

Drugs. $d$-Amphetamine (NIDA) was administered either intraperitoneally $(1 \mathrm{ml} / \mathrm{kg})$ or subcutaneously $(2 \mathrm{ml} / \mathrm{kg}$ to avoid local irritation that might be produced by high concentrations). Doses are expressed as the free base. There were no significant differences between the results of the intraperitoneal and subcutaneous treatments; therefore, data were combined where appropriate.

General procedures. (See Results for specific details.) Animals were placed in individual experimental chambers at least $3 \mathrm{~d}$ before the beginning of drug treatment. To facilitate habituation to the chambers, animals were handled and injected with saline at least once a day. During the remainder of the day, animals were not disturbed and their behavior was monitored continuously.

Escalating dose phase. In a series of preliminary studies, we examined the effects of a number of different escalating dose regimens on the ability of the animals to tolerate subsequent high-dose binge exposures without displaying any adverse signs such as convulsions, ataxia, persistent high core temperature, or any behavioral evidence of ill health (e.g., lack of grooming). We found the dosage parameters summarized in Table 1 to satisfy these criteria. For the Escalating Dose cycles, animals received three injections per day for $4 \mathrm{~d}$, beginning with a $1.0 \mathrm{mg} / \mathrm{kg}$ dose of AMPH and ending with a dose of $8 \mathrm{mg} / \mathrm{kg}$ on the fourth day of the cycle. Single-dose challenges were inserted at various times after the course of this treatment. Other groups served as controls. Groups that continued on to the binge phase of this experiment received two injections of saline on day 5 , and binge injections were initiated on day 6 . During the Run phase animals received four injections of $8 \mathrm{mg} / \mathrm{kg} \mathrm{AMPH}$, every $2 \mathrm{hr}$, beginning at 8 A.M. and ending at 2 P.M. Animals were exposed to this daily binge regimen for up to 9 consecutive days, and different groups were challenged with a single dose of AMPH $(2.5$ or $8.0 \mathrm{mg} / \mathrm{kg})$ at various times during and after this treatment phase. For all experiments, $n=$ $8-10$ per group. Specific details for each experiment are included in Results.

For dialysis studies, animals were stereotaxically implanted with guide cannulae using procedures previously described in detail (Kuczenski and Segal, 1989). Guide cannulae extended $2.6 \mathrm{~mm}$ below the surface of the skull and were aimed at the caudate-putamen $(1.0 \mathrm{~mm}$ anterior to bregma, $2.8 \mathrm{~mm}$ lateral, and $6.2 \mathrm{~mm}$ below dura), the hippocampus (5.8 $\mathrm{mm}$ anterior, $4.8 \mathrm{~mm}$ lateral, $7.5 \mathrm{~mm}$ below dura), and/or the nucleus accumbens ( $2.2 \mathrm{~mm}$ anterior, $1.5 \mathrm{~mm}$ lateral, $7.8 \mathrm{~mm}$ below dura). After surgery, animals were housed individually and allowed at least 1 week to recover before receiving any treatment.

Each rat was placed in an experimental chamber, and the dialysis probes were inserted on the day before treatment (3:00-4:00 P.M.) to allow for acclimation to the test environment and for adequate equilibration of the dialysis probes. The dialysis chambers were essentially identical to the behavioral chambers described above, with the exceptions that the "home" compartment and hanging stimulus were removed to prevent interferences introduced by the dialysis methodology. Concentric microdialysis probes were constructed of Spectra/Por hollow fiber (molecular weight cutoff, 6000; o.d. $250 \mu \mathrm{M}$ ) as described previously (Kuczenski and Segal, 1989). The length of the active probe membrane was 3 $\mathrm{mm}$ for caudate-putamen and hippocampus and $1.25 \mathrm{~mm}$ for nucleus accumbens. Probes were perfused with artificial CSF containing (in $\mathrm{mM}$ ): $147 \mathrm{NaCl}, 1.2 \mathrm{CaCl}_{2}, 0.9 \mathrm{MgCl}_{2}$, and $4.0 \mathrm{KCl}$ delivered by a microinfusion pump $(0.5$ or $1.5 \mu \mathrm{l} / \mathrm{min})$ via $50 \mathrm{~cm}$ of Micro-line ethyl vinyl acetate tubing connected to a fluid swivel. Dialysate was collected through glass capillary tubing into vials containing $20 \mu \mathrm{l}$ of $25 \%$ methanol, $0.2 \mathrm{M}$ sodium citrate, $\mathrm{pH}$ 3.8. Under these conditions, dialysate dopamine (DA), serotonin (5HT), norepinephrine (NE), and metabolites were stable throughout the collection and analysis interval. Samples were collected outside the experimental chamber to avoid disturbing the animal. Individual probe recoveries were estimated by sampling a standard DA solution in vitro. Preliminary studies indicated that individual probe recoveries for DA, 5HT, and NE were similar. At the end of the experiment, each animal was perfused with formalin for histological verification of probe placements.

Dialysate samples were collected every 10,20 , or 30 min (see Results for specific experiments) and were assayed for DA, 3,4-dihydroxyphenylacetic acid (DOPAC), homovanillic acid (HVA), 3-methoxytyramine (3MT), 5-hydroxyindoleacetic acid (HIAA), and 5HT in caudate-putamen and nucleus accumbens samples or, for NE, in hippocampus by HPLC with electrochemical detection. In all experiments, solutions of standards revealed a clean separation between 3MT and 5HT. Each HPLC-EC consisted of a $100 \mathrm{~mm} \times 4.6 \mathrm{~mm}$ ODS-C18 $3 \mu \mathrm{M}$ column (Regis) maintained at $40^{\circ} \mathrm{C}$ for DA $/ 5 \mathrm{HT}$ assays or at $30^{\circ}$ for $\mathrm{NE}$ assays. Mobile phase $(0.05 \mathrm{M}$ citric acid, $7 \%$ methanol, $0.1 \mathrm{~mm}$ $\mathrm{Na}_{2}$ EDTA, and $0.2 \mathrm{~mm}$ octane sulfonate adjusted to $\mathrm{pH} 4.0-4.5$ for $\mathrm{DA} / 5 \mathrm{HT} ; 4 \%$ methanol and $1.5 \mathrm{~mm}$ octane sulfonate for NE) was delivered at $0.6 \mathrm{ml} / \mathrm{min}$ by a Waters model 510 pump. Amines were detected with Waters 460 detectors with glassy carbon electrodes maintained at $+0.65 \mathrm{~V}$ relative to a $\mathrm{Ag} / \mathrm{AgCl}$ reference electrode. Concentrations were estimated from peak areas using a Waters Maxima 820 data station. Substances in the dialysates were corrected for individual probe recoveries to account for this source of variability and, although the exact relationship between dialysate concentration and actual extracellular transmitter content is not clear (Wages et al., 1986; Church and Justice, 1987; Benveniste et al., 1989; Stahle et al., 1991), values are presented as dialysate concentration to allow for meaningful comparisons to other data in the literature.

Data analysis. Behavioral and neurochemical data were analyzed statistically using repeated-measures ANOVA and $t$ tests with Bonferroni corrections for specific group/time comparisons.

\section{RESULTS}

\section{Behavioral effects}

The Escalating Dose phase of the treatment resulted in a combination of sensitization and tolerance (Fig. 1). As demonstrated previously (Segal, 1975a; Segal et al., 1980; Segal and Kuczenski, 1994), an acute injection of a relatively high dose of AMPH (8.0 $\mathrm{mg} / \mathrm{kg}$ ) produced a multiphasic response pattern that included a rapid onset of the stereotypy phase consisting primarily of fo- 


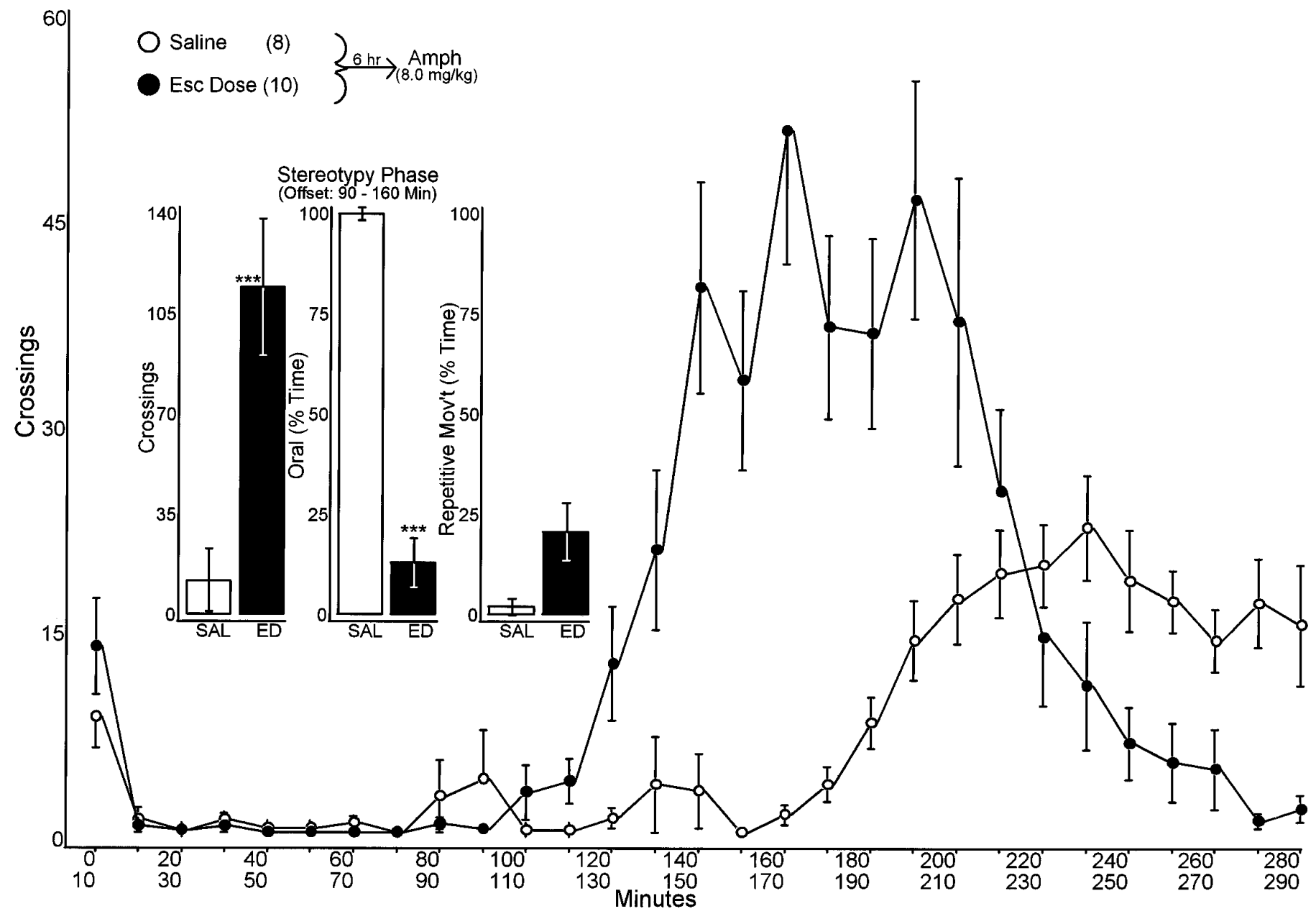

Figure 1. Temporal pattern of the locomotor response to the last injection of AMPH $(8.0 \mathrm{mg} / \mathrm{kg})$ during the Escalating Dose $(E D)$ pretreatment regimen (see Table 1). Control animals received an equivalent number of saline injections before AMPH. Histograms represent the cumulated response over the indicated interval. Values are the mean \pm SEM. Significant differences from the Saline group, ${ }^{* *} p \leq 0.001$.

cused, repetitive biting and licking and during which locomotion was absent (Fig. 1). After the stereotypy phase, which persisted for $\sim 2.5 \mathrm{hr}$ (10-160 min), a poststereotypy phase emerged during which locomotion predominated. The response profile of the acute $8.0 \mathrm{mg} / \mathrm{kg}$ dose was consistent with our previous doseresponse results (Segal, 1975a; Kuczenski and Segal, 1988), which showed that for acute doses greater than $\sim 5 \mathrm{mg} / \mathrm{kg}$, the magnitude of the poststereotypy phase is actually lower than the level of activity that occurs during this phase after more moderate doses of AMPH, although the duration of both the stereotypy and poststereotypy phases continue to be dose-related. By contrast to the acute effects of $8.0 \mathrm{mg} / \mathrm{kg} \mathrm{AMPH}$, the response to the last injection of the Escalating Dose cycle (i.e., $8.0 \mathrm{mg} / \mathrm{kg}$ ) was significantly altered, most notably by the displacement of a large portion of the stereotypy phase with enhanced locomotor activity (Fig. 1). In addition, the duration of the whole response was significantly diminished (Crossings, 230-290 min interval; Acute vs Escalating Dose, $135 \pm 38$ vs $17 \pm 6 ; p<0.02)$. These alterations in the locomotor pattern were also apparent in the expression of the stereotypy (Fig. 1); that is, oral stereotypy for the Escalating Dose group was significantly reduced during the latter portion of the stereotypy phase (90-160 min). For some animals, the oral stereotypy was displaced by repetitive head and limb movements (a lower-dose form of stereotypy). During this interval, however, most animals exhibited a relatively rapid transition from oral stereotypy to locomotion. This emergent behavioral profile differs in its temporal and quantitative features from lower or higher doses and, therefore, is distinct from any acute dose of AMPH.

Most of these same effects are also identifiable during the subsequent Run ( $8 \mathrm{mg} / \mathrm{kg}$ every $2 \mathrm{hr}$ for 4 injections) exposures (Figs. 2-5). The relatively pronounced decrease in the duration of the stereotypy phase and the increase in locomotion that emerged with repeated runs are particularly evident in the comparison of the locomotor (Fig. 2) and stereotypy (Fig. 3) profiles for the last injection of each run with the corresponding response patterns resulting from acute and Single Daily Injections after either saline or the Escalating Dose pretreatment. By the ninth run, some animals exhibited episodes of locomotor activity throughout the stereotypy phase, which became progressively more pronounced with successive injections during the run (Fig. 4). In addition, the poststereotypy locomotor activation appeared sooner, as evidenced in both the locomotor (Fig. 2) and the stereotypy (Fig. 3) profiles. Furthermore, unlike the effect of the Escalating Dose treatment alone, the high level of locomotion during the poststereotypy phase persisted for a longer duration than after the other treatments (Fig. 2). During this period, animals made very rapid darting movements between quadrants and, in fact, the difference 


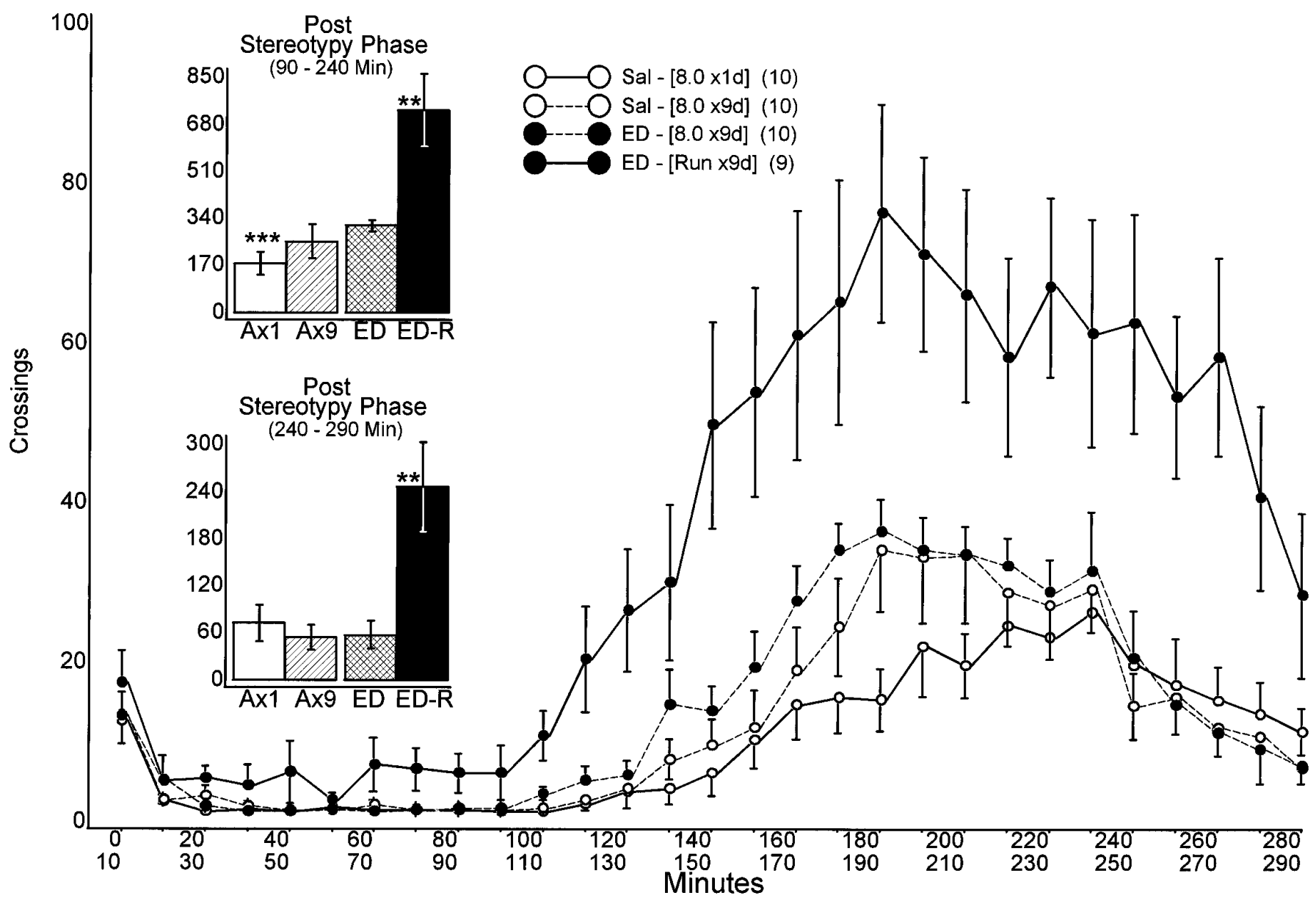

Figure 2. The temporal pattern of locomotion after the first $[\mathrm{Sal}-(8.0 \times 1 \mathrm{~d})]$ or ninth $[\mathrm{Sal}-(8.0 \times 9 \mathrm{~d})]$ Single Daily Injection of AMPH $(8.0 \mathrm{mg} / \mathrm{kg})$ in SAL-pretreated animals compared with the response to the ninth Single Daily Injection of AMPH [ED - $(8.0 \times 9 \mathrm{~d})]$ or the fourth AMPH injection of the ninth run [ED - (Run $\times 9 \mathrm{~d})]$ in Escalating Dose $(\mathrm{ED})$-pretreated animals. Histograms represent the response cumulated over the indicated intervals. Values are the mean \pm SEM. Significantly different from the ninth Single Daily Injection of the Escalating Dose-pretreated animals, $p \leq 0.01 ; * * * p \leq$ 0.001 .

in crossings between these rats and controls could be accounted for by successive crossings that occurred within $<2 \mathrm{sec}$ of each other. The animals remained very active even when not ambulating, often displaying intense nose-poking between the floor grids and very occasional focused oral or repetitive head and limb stereotypies. These qualitative characteristics clearly distinguished the response during the runs from the behavior associated with the other treatments and suggested that during much of the poststereotypy period, rats were in an extremely agitated or even frenzied state. This increase in the locomotor component of the response and corresponding decrease in the duration of the continuous stereotypy phase occurred progressively over the course of successive runs (Fig. 5).

The relatively selective enhancement of locomotion persisted in response to AMPH challenge. Different groups of animals were challenged with a lower dose of AMPH $(2.5 \mathrm{mg} / \mathrm{kg}) 9 \mathrm{~d}$ after the fifth consecutive daily run (Fig. 6). After the Escalating DoseRun exposure, locomotion was significantly greater both before (0-20 $\mathrm{min})$ and after (70-240 $\mathrm{min})$ the stereotypy phase when compared with the sensitized response that emerged with the Single Daily Injections treatment.

Activity in response to daily saline injections and during the dark phase was significantly altered for at least several days after withdrawal from the nine-run treatment (Figs. 7, 8). The locomotor response to saline administration was initially depressed in Escalating Dose-Run pretreated animals but gradually increased after several days, especially during the first 5-10 min after injection, achieving a significant elevation between the fourth and seventh days of withdrawal (Fig. 7). By contrast, spontaneous activity, particularly during the period when control animals exhibited the greatest night-time activity (7-9 P.M.), was significantly reduced for the first 2 nights after drug-free days (Fig. 8); ingestive behaviors (time spent eating and drinking) were also significantly depressed over this same period.

Whereas nondrugged controls gradually gained weight throughout the course of the experiment $(\sim 1 \mathrm{gm} / \mathrm{d})$, the weight of the Escalating Dose-Run group declined to a level of $\sim 80 \%$ of controls by the ninth run. At no time did these animals exhibit obvious signs of ill health, and their weight rapidly recovered after cessation of drug treatment and was no longer significantly different from controls after $\sim 2$ weeks of withdrawal.

\section{Neurochemical changes}

Regional tissue levels of DA, 5HT, and/or NE were determined at various times during or after the first and fifth runs. The Escalating Dose pretreatment had no effect on caudate-putamen DA 


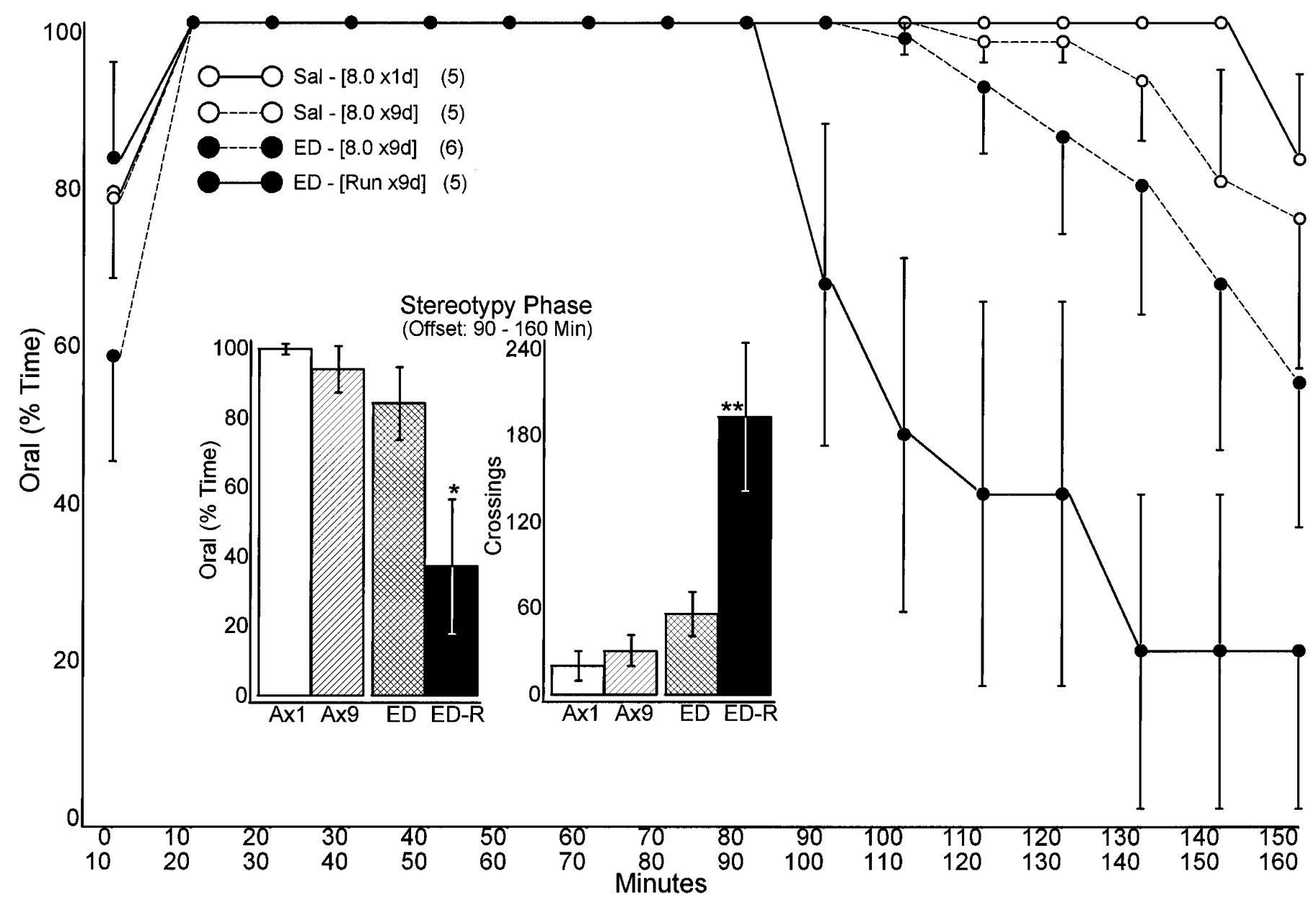

Figure 3. Temporal pattern of oral stereotypy after the first [Sal $-(8.0 \times 1 \mathrm{~d})]$ or ninth [Sal $-(8.0 \times 9 \mathrm{~d})]$ single daily injection of AMPH $(8.0 \mathrm{mg} / \mathrm{kg})$ in SAL-pretreated animals compared with the response to the ninth single daily injection of AMPH [ED $-(8.0 \times 9 \mathrm{~d})]$ or the fourth AMPH injection of the ninth run [ED - (Run $\times 9 \mathrm{~d})]$ in Escalating Dose-pretreated animals. Histograms represent the response cumulated over the indicated intervals. Values are the mean \pm SEM. Comparison of $\%$ time in oral behaviors with crossings reveals the reciprocal relationship between focused stereotypy and locomotion. Significantly different from the first single daily injection response $(A \times 1),{ }^{*} p \leq 0.05 ; * * \leq 0.01$.

Table 2. Tissue levels of monoamines after the escalating dose-run treatment

\begin{tabular}{|c|c|c|c|c|}
\hline \multirow[b]{2}{*}{ Treatment $(n)$} & \multicolumn{2}{|c|}{ Caudate-putamen } & \multicolumn{2}{|c|}{ Hippocampus } \\
\hline & $\begin{array}{l}\text { DA } \\
(\mathrm{pmol} / \mathrm{gm})\end{array}$ & $5-\mathrm{HT}$ & $\begin{array}{l}\mathrm{NE} \\
(\mathrm{pmol} / \mathrm{gm})\end{array}$ & $5-\mathrm{HT}$ \\
\hline Control (13) & $95.0 \pm 2.1$ & $3.27 \pm 0.10$ & $2.22 \pm 0.07$ & $2.41 \pm 0.11$ \\
\hline 3 d withdrawal (6) & $73.2 \pm 5.4^{a}$ & $2.74 \pm 0.16$ & $0.90 \pm 0.03^{a}$ & $1.56 \pm 0.13^{a}$ \\
\hline 3 week withdrawal (7) & $74.9 \pm 3.1^{a}$ & $2.94 \pm 0.17$ & $2.30 \pm 0.06^{b}$ & $2.26 \pm 0.11^{b}$ \\
\hline
\end{tabular}

$a_{p}<0.01$ compared to control.

${ }^{b} p<0.01$ compared to $3 \mathrm{~d}$ withdrawal.

$(71.4 \pm 1.1 \mathrm{vs} 75.2 \pm 1.4 \mathrm{pmol} / \mathrm{gm}$ tissue in controls $)$, but $20 \mathrm{~min}$ after the fourth injection of the first run, caudate-putamen DA was reduced to $\sim 74 \%$ of controls $(55.8 \pm 4.78 \mathrm{pmol} / \mathrm{gm}$ tissue $)$. This decrease in DA occurred concomitant with a $10-15 \%$ increase in caudate-putamen AMPH levels $(115 \pm 8 \mathrm{nmol} / \mathrm{gm} 20$ min after a single injection, vs $131 \pm 5 \mathrm{nmol} / \mathrm{gm} 20 \mathrm{~min}$ after the fourth injection) (Melega et al., 1995). Approximately similar reductions in tissue DA were detected at $3 \mathrm{~d}$ and 3 weeks after the fifth run (Table 2). In contrast, whereas caudate-putamen 5HT was not significantly diminished, both hippocampal NE and 5HT were substantially reduced $3 \mathrm{~d}$ after the last run $(60 \%$ and $35 \%$, respectively) but fully recovered by 3 weeks. More recently, we have found similar patterns of regional monoamine depletion after longer run schedules using the same or lower doses $(4.0 \mathrm{mg} / \mathrm{kg})$.

In vivo microdialysis procedures were used in freely moving animals to determine the effects of the Escalating Dose-Run treatment on regional extracellular monoamine levels. In one study, animals were first exposed to the Escalating Dose regimen and were then monitored for caudate-putamen DA and 5HT as 


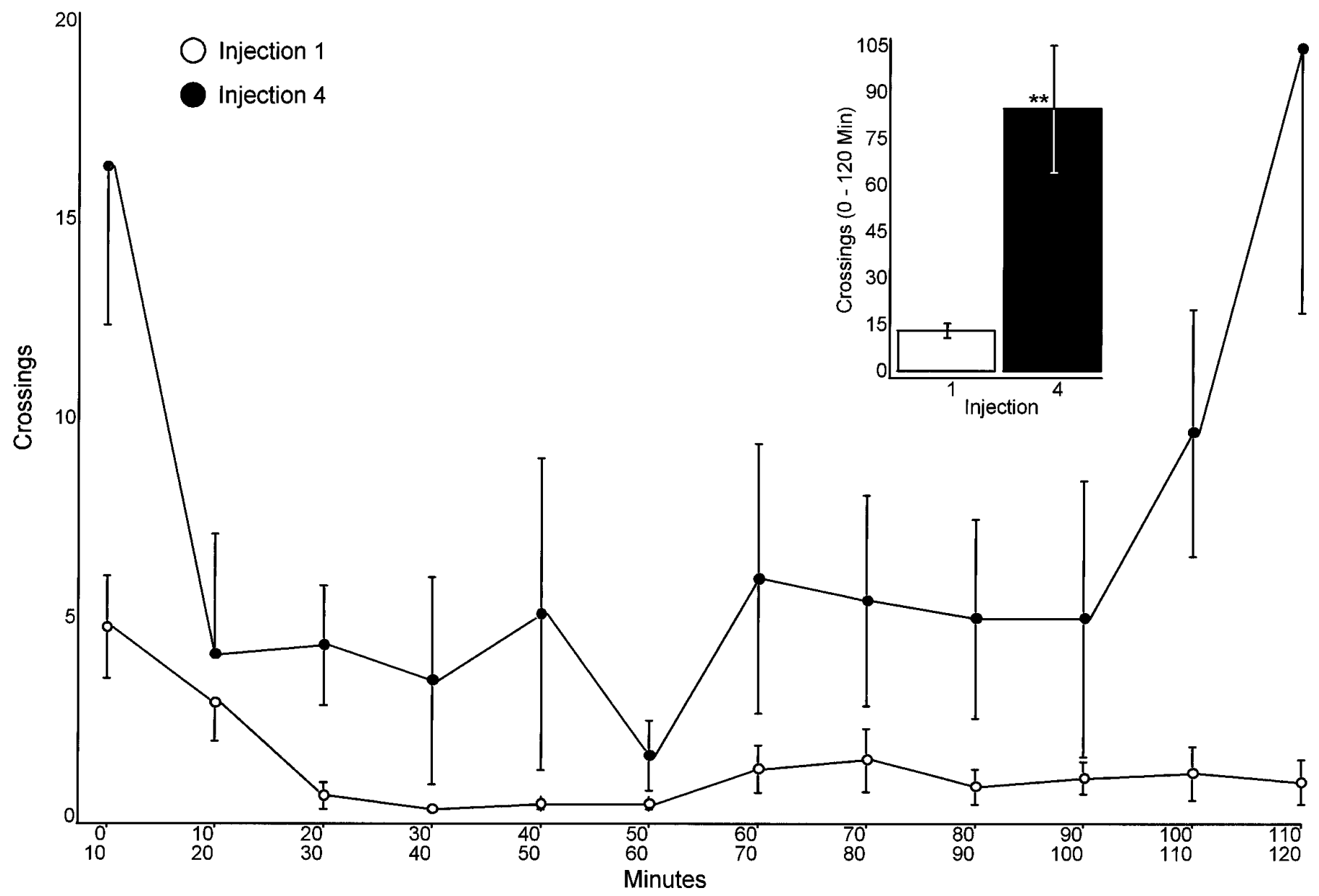

Figure 4. Locomotor activity during the typical stereotypy phase (see Results) after the first and fourth injections of Run 9. Values are the mean \pm SEM. Histograms represent the response cumulated over the $0-120 \mathrm{~min}$ interval. Significantly different from the first injection of the run, $* * p \leq 0.01$.

well as hippocampal NE (Fig. 9) or nucleus accumbens DA and 5HT (Fig. 10) during the course of a four-injection run. Control animals were pretreated with saline and then received three injections of saline followed by a single injection of AMPH $(8.0$ $\mathrm{mg} / \mathrm{kg}$ ) during the run session. Baseline monoamine and metabolite levels in saline and Escalating Dose pretreated animals were not significantly different; likewise, the Escalating Dose pretreatment did not alter the monoamine responses to the first AMPH injection (Figs. 9, 10). However, for both caudate-putamen (Fig. 9) and nucleus accumbens (Fig. 10), the DA response (peak levels and area under the curve) progressively declined with successive injections during the run. A similar pattern was obtained for caudate-putamen and nucleus accumbens 5HT (Figs. 9, 10). In contrast to these effects, the hippocampal NE response remained relatively unaltered during the run and, in fact, tended to increase with successive injections. Similar results were observed for frontal cortex NE in a separate group of animals (data not shown).

By the fourth run, baseline levels of caudate-putamen DA and $5 \mathrm{HT}$ were reduced, but only the $5 \mathrm{HT}$ reduction was statistically significant (DA, $33.1 \pm 4.5$ vs $23.3 \pm 3.4 \mathrm{nM}$; $5 \mathrm{HT}, 1.7 \pm 0.3$ vs $1.0 \pm 0.2 \mathrm{nM})$. However, the response of both monoamines was significantly attenuated (Fig. 11). For caudate-putamen DA, comparison of the first and fourth runs revealed that the response sequence began at a lower level during the fourth run and declined further with successive injections so that the DA response after the fourth injection remained significantly lower than during the first run. For 5HT, the initial difference between the first and fourth runs was no longer apparent after the fourth injection.

In contrast to the effect of successive runs on the caudateputamen DA and 5HT responses, the hippocampus NE response (Fig. 11) progressively increased between the first and fourth injections during the fourth run, although it was significantly lower after the first injection of the fourth run compared with the first injection of the first run.

\section{DISCUSSION}

Clinical evidence indicates that stimulant-induced psychopathology, particularly in the form of paranoid psychosis, is most often associated with a chronic high-dose, multiple daily exposure pattern of stimulant abuse (for review, see Angrist, 1994b). Most individuals appear to be without significant psychopathology during the initial phase of Escalating Dose usage, during which tolerance develops to the potentially lethal sympathomimetic actions of these drugs (Fischman and Schuster, 1974; Schmidt et al., 1985b; Angrist, 1994b). Tolerance to the sympathomimetic effects enables users to administer higher doses more frequently to achieve a more intense euphoria and/or to overcome tolerance that may also develop to the euphorigenic effects (Sato, 1986; Angrist, 1987; Gawin and Ellinwood, 1988; Angrist, 1994b; Gawin and Khalsa, 1996). Importantly, it appears to be during the course of multiple daily administrations (i.e., "binges" or "runs"), following the Escalating Dose phase, that paranoid psychosis is most 


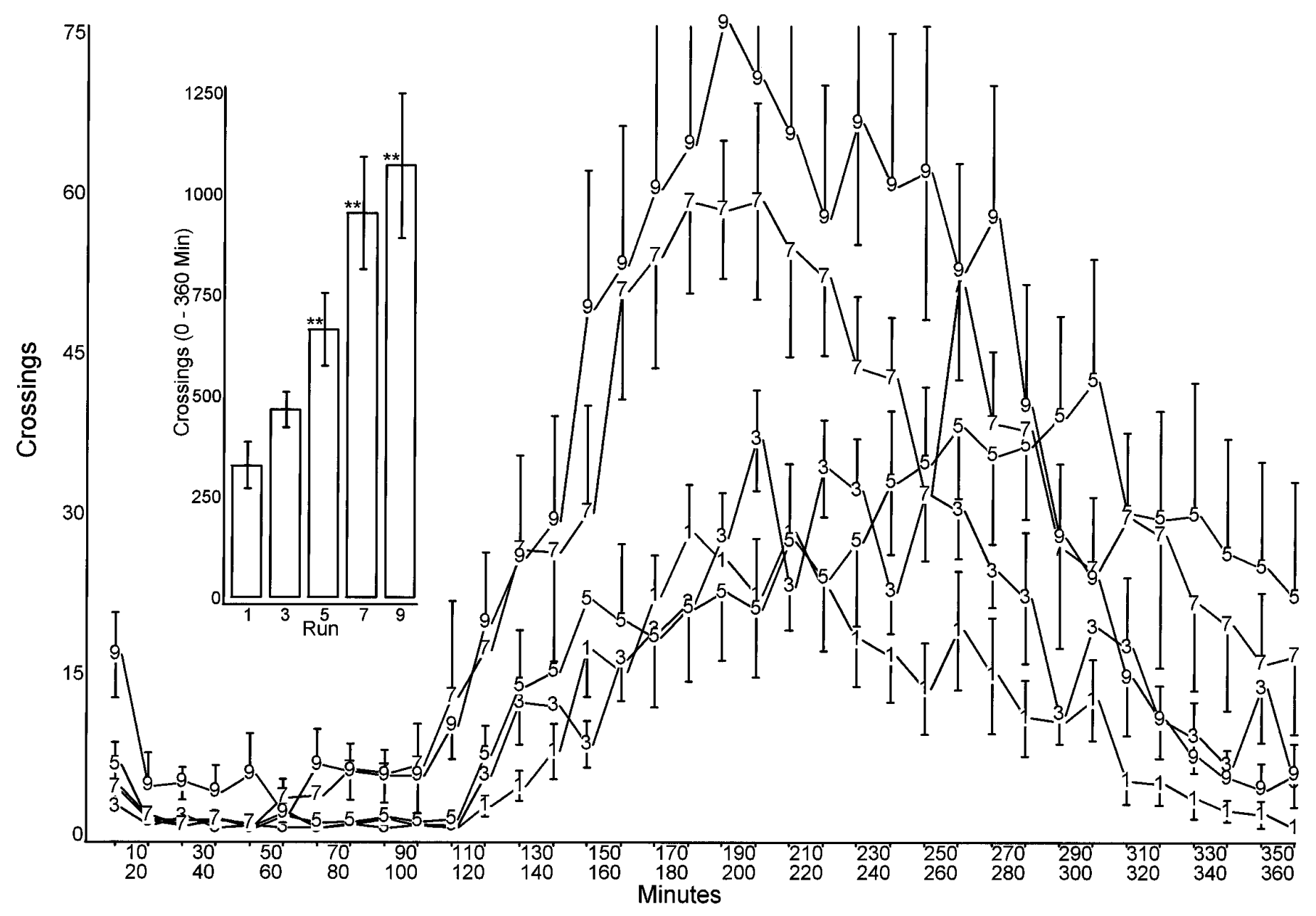

Figure 5. The locomotor response to the fourth injection of Runs 1, 3, 5, 7, 9. Values are the mean \pm SEM. Histograms represent the response over the 0-360 min interval. Significantly different from Run $1,{ }^{* *} p \leq 0.01$.

likely to appear (Kramer, 1972; Angrist, 1994b; Unterwald et al., 1994; Gawin and Khalsa, 1996); in fact, most evidence suggests that discontinuation of drug usage usually results in a rapid decline of the psychosis, closely paralleling drug urine levels (Angrist and Gershon, 1971; Davis and Schlemmer, 1980; Angrist, 1994b). These observations provide an important framework for basic researchers who are interested in developing animal models for the behavioral processes and neurochemical mechanisms that may be involved in stimulant psychosis. Although we and others have suggested that sensitization and the underlying neurochemical changes produced by intermittent repeated stimulant administration may be implicated in stimulant psychosis, a more accurate model may require the use of treatment conditions that more closely simulate the most relevant patterns of stimulant abuse in humans (Segal and Mandell, 1974; Segal and Janowsky, 1978; Angrist, 1994b; Gawin and Khalsa, 1996). Therefore, we engaged in a series of studies to identify behavioral and neurochemical changes in animals during their exposure to an Escalating DoseRun regimen of AMPH administration.

\section{Behavioral effects of Escalating Dose-Run treatment regimen}

The behavioral response to amphetamine at the end of the Escalating Dose pretreatment was comparable in most respects with the pattern of response alterations typically observed with re- peated intermittent injections of moderate to high doses of amphetamine (Segal, 1975a; Rebec and Segal, 1980; Segal et al., 1980). After the Escalating Dose phase, repeated daily exposure to high-dose runs produced an altered behavioral profile, which was both qualitatively and quantitatively different from that observed with any of the other treatment conditions. The magnitude of the poststereotypy locomotor response progressively increased, whereas the duration of the stereotypy phase actually decreased. In fact, by the ninth run, many animals displayed periodic episodes of locomotion throughout the time period during which acute doses produced intense stereotypy in the absence of any locomotion. In this regard, it is important to note that at higher acute doses, and correspondingly higher brain concentrations of AMPH, the stereotypy phase is increased both with respect to intensity and to duration, whereas the magnitude of poststereotypy locomotion is actually somewhat diminished, although it is prolonged in a dose-dependent manner (see Results). Therefore, this behavioral pattern cannot be explained simply as a result of the higher brain levels that accumulate through the course of each run. This is supported further by the persistence of the altered behavioral profile in response to single-dose challenge. Furthermore, this profile does not occur with repeated Single Daily Injections of high doses, with or without previous exposure to the Escalating Dose treatment and, in our experience, high-dose 


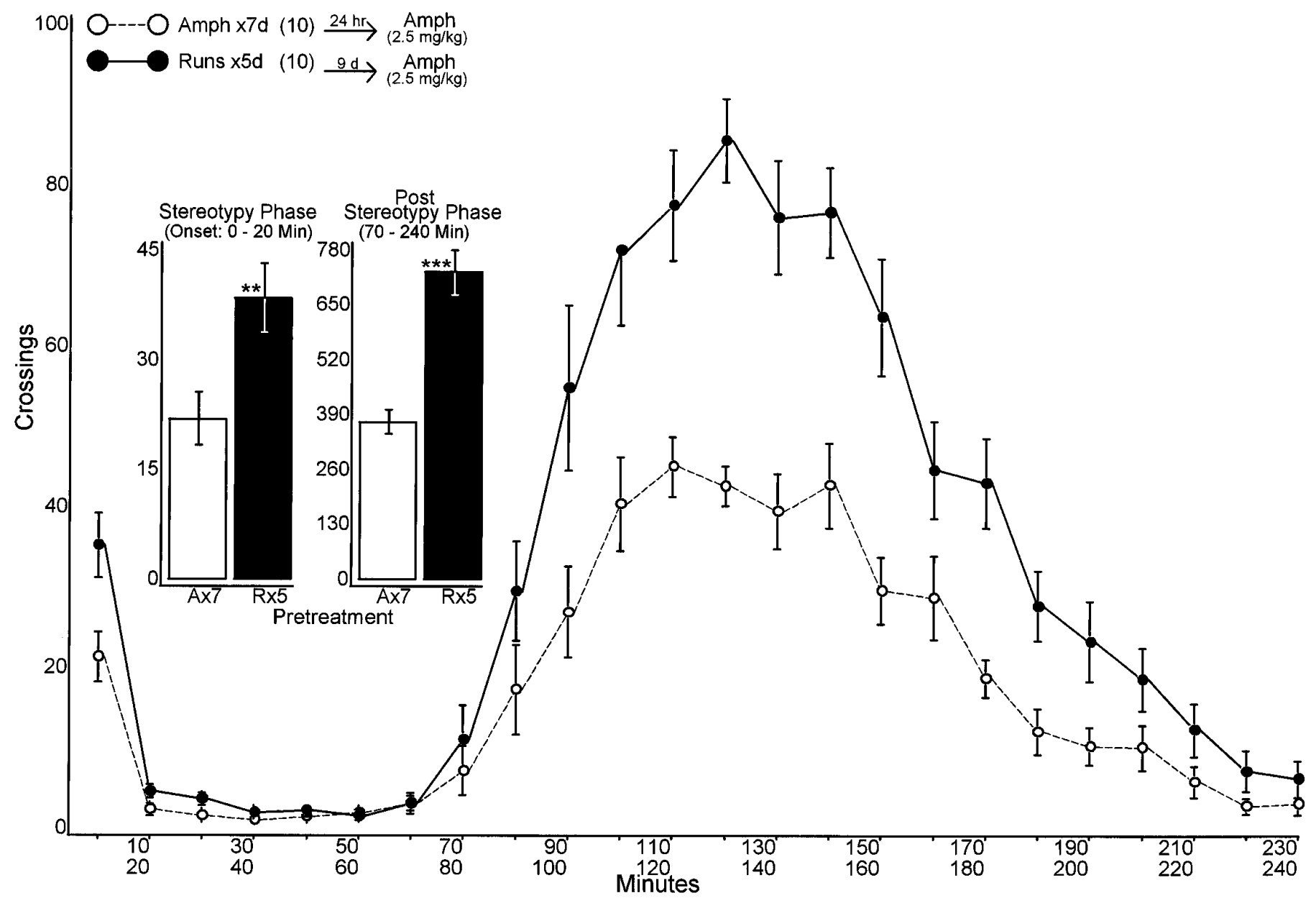

Figure 6. The locomotor response to AMPH $(2.5 \mathrm{mg} / \mathrm{kg}) 24 \mathrm{hr}$ after seven Single Daily Injections of AMPH (2.5 mg/kg) compared with the response to AMPH $(2.5 \mathrm{mg} / \mathrm{kg}) 9 \mathrm{~d}$ after five runs in Escalating Dose-pretreated animals. Values are the mean \pm SEM. Histograms represent the responses cumulated over the intervals indicated. Significantly different from the single daily injection AMPH group $(A \times 7),{ }^{* *} \mathrm{p} \leq 0.01 ; * * * p \leq 0.001$.

repeated runs in the absence of previous Escalating Dose treatment results in debilitation or death of most of the animals. Therefore, the combined Escalating Dose-Run regimen seems to be required for the development of this unique behavioral pattern that includes an admixture of apparent tolerance, particularly in the duration of the stereotypy phase, and sensitization of the locomotor component of the response.

\section{Neurochemical correlates of Escalating Dose-Binge amphetamine administration}

Despite the gradual accumulation of AMPH during the first run, the extracellular DA levels in both caudate-putamen and nucleus accumbens progressively declined with successive injections. This decrease in the DA response within a run corresponds to an enhanced behavioral effect apparent in at least some features of the response. Thus, these results are consistent with our previous findings (Segal and Kuczenski, 1992a,b) that a more rapid onset of stereotypy and an increase in poststereotypy hyperactivity (both primary indices of sensitization resulting from Single Daily Injections of moderate to high stimulant doses) can be expressed concomitant with a diminished DA response to AMPH. After repeated runs, a similar pattern was evident in caudate-putamen extracellular DA and, in addition, the response to the first injection of the run was significantly diminished. In the current series of studies, nucleus accumbens DA was not determined after multiple runs; however, converging evidence indicates that caudate-putamen DA is more responsive than is nucleus accumbens DA to the depleting effects of AMPH (Ellison et al., 1978; Ellison and Eison, 1983; Castañeda et al., 1990; Swerdlow et al., 1991; Paulson and Robinson, 1995). The results of a recent study of human chronic methamphetamine users are consistent with this interpretation (Wilson et al., 1996). Therefore, it is conceivable that the temporal pattern that emerges with repeated runs including, most prominently, a decrease in the duration of the stereotypy phase and an increase in the magnitude of the locomotor activation, is a consequence of a progressive shift toward a relatively greater role for the mesolimbic pathway in the expression of the behavioral response. This temporal pattern is consistent with previous observations regarding the competitive interaction between these two primary behavioral components of the response (Segal, 1975b; Segal and Schuckit, 1983; Whishaw et al., 1992).

Despite the critical role of DA in the stimulant response, however, converging evidence clearly demonstrates a significant dissociation between the quantitative features of the extracellular DA and behavioral responses to acute (Kuczenski and Segal, 1989, 1990; Kuczenski et al., 1991) and chronic (Segal and Kuczenski, 1992a; Kalivas and Duffy, 1993; Wolf et al., 1993, 1994; Paulson and Robinson, 1995) stimulant administration. In fact, the chronic administration of amphetamine-like stimulants affects 


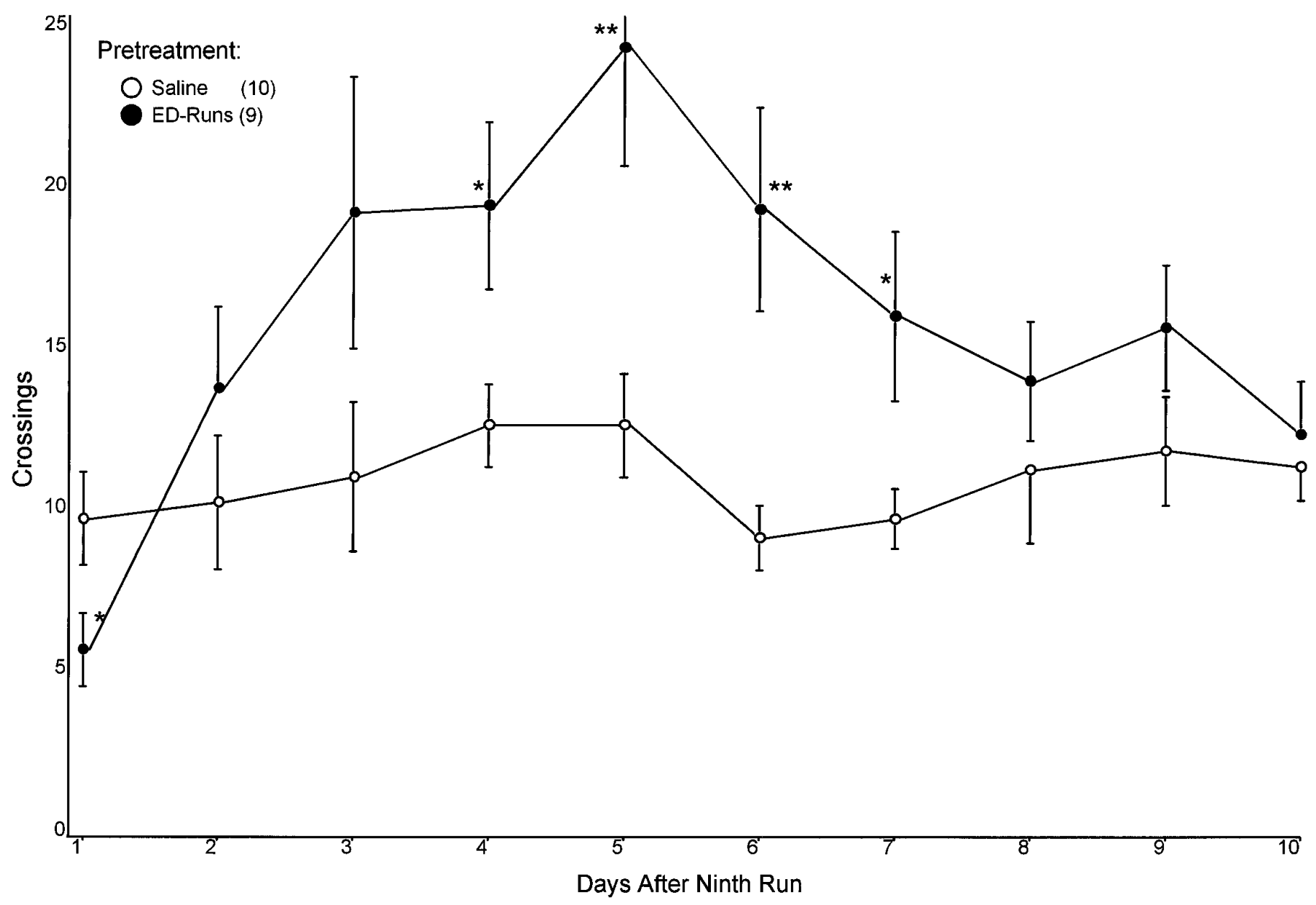

Figure 7. The locomotor response (0-10 $\mathrm{min})$ to SAL injections on consecutive days after pretreatment with SAL or ED-Runs (nine runs). Values are the mean \pm SEM. Significant difference from the corresponding response in SAL-pretreated animals, ${ }^{*} p \leq 0.05 ;{ }^{* *} p \leq 0.01$.

a variety of neurochemical, neurophysiological, and molecular changes, including modifications in pre- and postsynaptic receptor function as well as alterations in a variety of other neurotransmitter systems, and these changes are likely to be involved in the behavioral alterations associated with repeated AMPH treatment (for review, see Nestler, 1994; Hyman, 1996; Hyman and Nestler, 1996). In this regard, our present results also showed that the effects of the Escalating Dose-Run treatment on caudateputamen and nucleus accumbens extracellular 5HT paralleled the DA responses, although unlike DA, the caudate-putamen 5HT response during the fourth run showed no additional decline after the first injection.

Although the role of 5HT in the stimulant response is not well defined, some evidence suggests a suppressive effect on locomotor activation (Brodie and Shore, 1957; Neill et al., 1972; Swonger and Rech, 1972; Mabry and Campbell, 1973; Breese et al., 1974; Jacobs et al., 1975; Geyer et al., 1976; Segal, 1976, 1977). Our more recent microdialysis studies suggested that caudateputamen 5HT may be particularly relevant to the higher dose effects of AMPH (Kuczenski and Segal, 1989). It is conceivable, therefore, that decreases in 5HT during the course of the Escalating Dose-Run treatment may contribute to the relative expression of locomotion and stereotypy, perhaps through a differential effect on caudate-putamen and nucleus accumbens output. In contrast to the progressively declining extracellular DA and 5HT responses during the Escalating Dose-Run treatment, the extracellular NE response remained relatively unaltered and, in fact, slightly increased during the course of repeated runs. We have suggested that NE may have an inhibitory effect on stereotypy (Florin et al., 1995), which is consistent with our present findings that a relative increase in the $\mathrm{NE} / \mathrm{DA}$ ratio corresponds to a shift toward progressively less stereotypy and more locomotion during the course of repeated runs.

Consistent with previous results (Paulson et al., 1991), the Escalating Dose treatment did not produce persistent depletions of tissue monoamines. However, although this gradual preexposure to successively higher doses of AMPH likely attenuated the more pronounced effect of high-dose runs (Schmidt et al., 1985a,b), we did find a reduction in caudate-putamen DA tissue levels that persisted for at least 3 weeks after the last run. In fact, a number of clinical researchers have suggested the possibility of moderate DA neurotoxicity resulting from prolonged AMPH abuse (Fischman et al., 1985; Gawin and Ellinwood, 1988; Lieberman et al., 1990; Fibiger, 1991; LeDuc and Mittleman, 1995; Gawin and Khalsa, 1996) and, in a recent study, postmortem caudate-putamen DA was found to be significantly reduced in human chronic methamphetamine users (Wilson et al., 1996). In this regard, it is likely that some monoamine depletion, at least partly contributes to the tolerance observed in the DA and 5HT responsivity during the AMPH run, because brain drug levels 


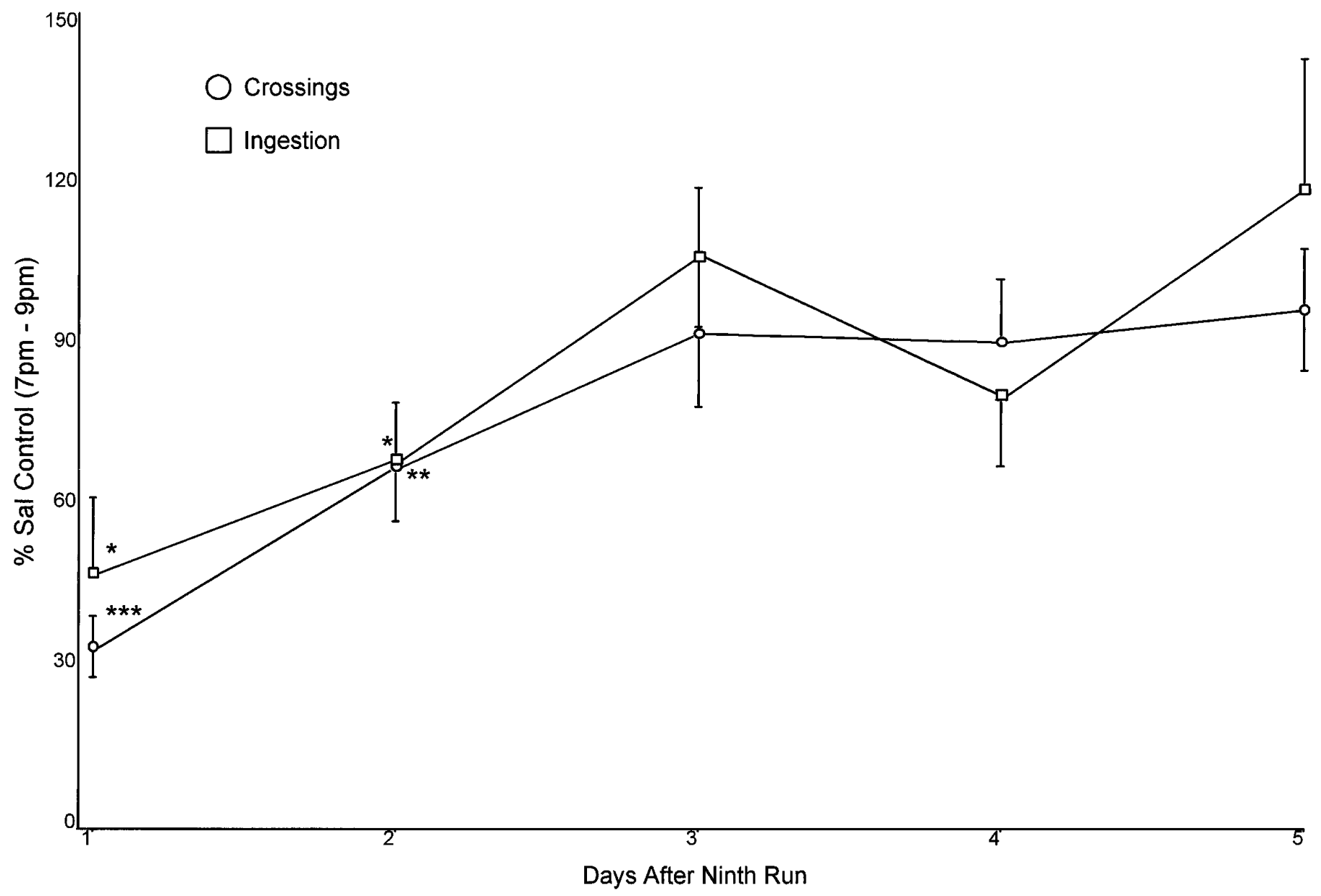

Figure 8. Locomotion and ingestion (time spent eating or drinking) during the first $2 \mathrm{hr}$ of the dark cycle (7-9 P.M.) for 5 consecutive drug-free days after the ninth run in Escalating Dose-Run-treated animals. Values are mean percent \pm SEM of the SAL-pretreated group; $n=10$ (SAL) and 9 (ED-Run). Significantly different from corresponding SAL responses, ${ }^{*} \mathrm{p} \leq 0.05 ;{ }^{* *} p \leq 0.01 ;{ }^{* *} p \leq 0.001$.

were significantly higher in response to the fourth compared with the first drug injection. Possible molecular mechanisms underlying these changes in the response to AMPH will be discussed in greater detail elsewhere.

\section{Relevance to stimulant effects in humans}

Several features of the response to the Escalating Dose-Run regimen resemble the behavioral effects in humans. For one, similar to the withdrawal response in stimulant abusers (Griffith et al., 1972; Gawin, 1991; Angrist, 1994b; Gawin and Khalsa, 1996), discontinuation of the Escalating Dose-Run treatment resulted in a depression, which persisted for several days, during the behaviorally active dark phase (Segal, 1975b; Robinson et al., 1988; Paulson et al., 1991; Paulson and Robinson, 1996). In addition, during the withdrawal period, the response to daily saline injections was significantly elevated for at least $4 \mathrm{~d}$ after an initial depression. This increased reaction to the cues associated with the injection procedure (i.e., a conditioned locomotor response) persisted for more injections than we have observed previously with other chronic paradigms and may be relevant to the conditioned responses in humans that are believed to contribute to craving and relapse (Gawin, 1991; Kleber, 1995; Berger et al., 1996; Gawin and Khalsa, 1996). Finally, the relatively selective locomotor augmentation persisted in response to challenge for at least 3 weeks after withdrawal. This observation is consistent with recent evi- dence that stimulant abusers who previously experienced druginduced psychosis required either lower doses or fewer successive drug administrations to reproduce the psychosis after a period of abstinence (Sato, 1986; Satel et al., 1991; Angrist, 1994a,b; Gawin and Khalsa, 1996).

One clue as to the possible clinical relevancy of the altered behavioral profile that results with the Escalating Dose-Run regimen is suggested by observations of stimulant abusers during periods when they displayed stimulant-induced perseverative response patterns (Rylander, 1969, 1980; Schiorring, 1977; Davis and Schlemmer, 1980). These clinical researchers reported that stimulant-induced stereotypies appeared to have a calming effect and that individuals became irritated and/or anxious when the stereotypy was interrupted. In this regard, it is important to note that the affect associated with AMPH psychosis is in the direction of anxiety and that anxiety appears to intensify progressively during the course of a binge before individuals experience frank paranoid delusions (Gawin and Ellinwood, 1988; Angrist, 1994b; Gawin and Khalsa, 1996).

Stereotyped behaviors in animals have also been considered by some to represent a coping mechanism that functions to reduce stress or excessive arousal through disengagement from external stimuli (Segal and Geyer, 1985; Mason, 1991; Mittleman et al., 1991). Thus, it is conceivable that stimulant-induced focused 

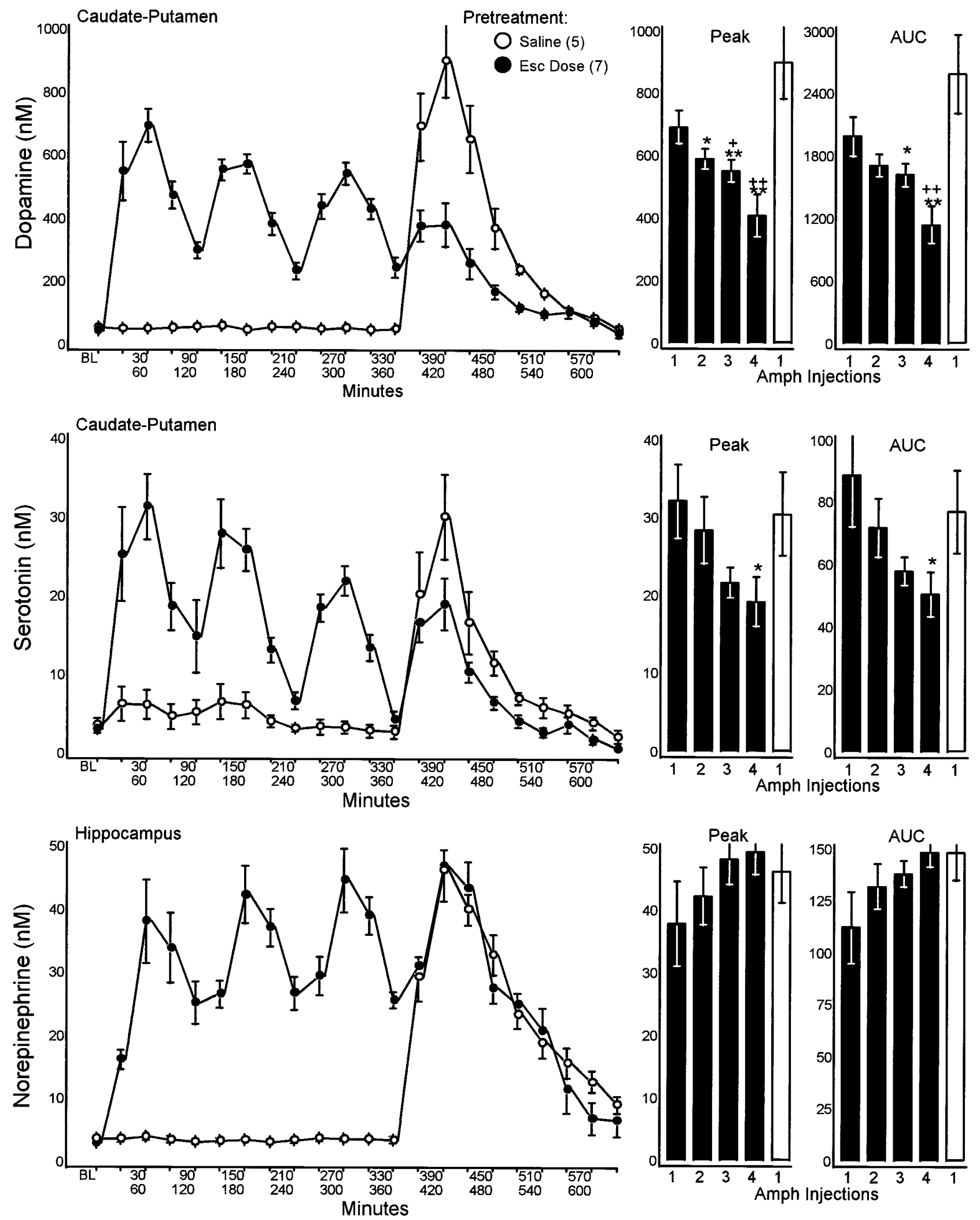

Figure 9. Extracellular neurotransmitter responses during an AMPH run. One group of animals was pretreated with the Escalating Dose pattern of AMPH and then challenged $36 \mathrm{hr}$ later with 4 injections of $8.0 \mathrm{mg} / \mathrm{kg}$ AMPH at $2 \mathrm{hr}$ intervals. Control animals (Saline) were pretreated with an equal number of injections of saline, and challenged with a single injection of $8.0 \mathrm{mg} / \mathrm{kg}$ AMPH. Top, Caudate-putamen DA; center, caudate-putamen 5HT; bottom, hippocampus NE (a similar pattern was obtained for the frontal cortex NE response). Dialysate samples were collected at 30 min intervals. There were no significant differences for any transmitter between the response to AMPH in the saline group and the first injection of AMPH in the Escalating Dose-Run group. $A U C$, Area under the curve for the $0-120$ min interval after each injection: ${ }^{*} p \leq 0.05 ; * * \leq 0.01$ compared with the first injection of the run; $+p \leq 0.05 ;++p \leq 0.01$ compared with the immediately preceding injection. 

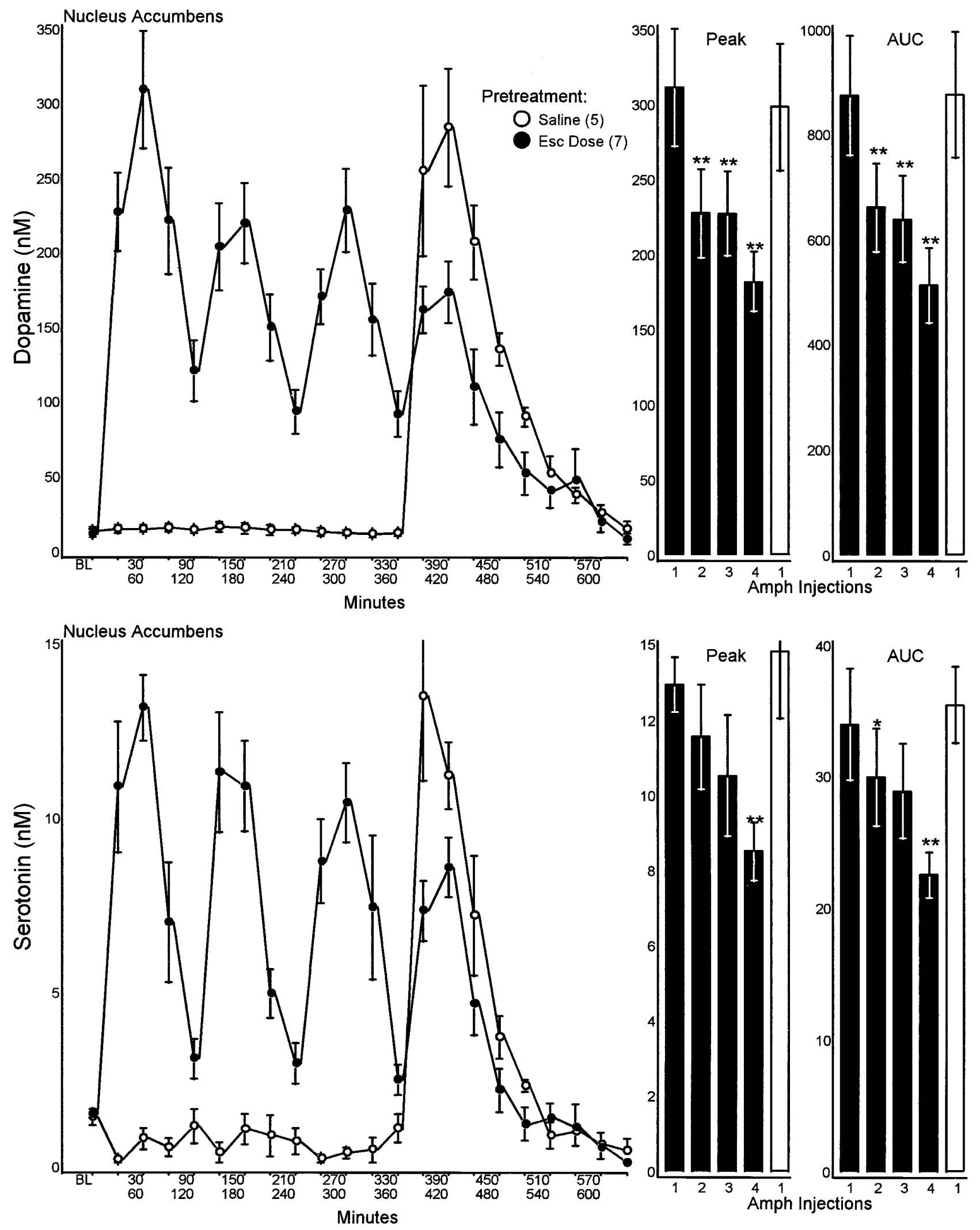

Figure 10. Nucleus accumbens DA (top) and 5HT (bottom) responses during an AMPH run. One group of animals was pretreated with the Escalating Dose treatment of AMPH and then challenged $36 \mathrm{hr}$ later with 4 injections of $8.0 \mathrm{mg} / \mathrm{kg}$ AMPH at $2 \mathrm{hr}$ intervals. Control animals (Saline) were pretreated with an equal number of saline injections and challenged with a single dose of $8.0 \mathrm{mg} / \mathrm{kg}$ AMPH. Dialysate samples were collected at 30 min intervals. There were no significant differences for either transmitter between the response to AMPH in the saline group and the first injection of AMPH in the Escalating Dose-Run group. AUC, Area under the curve for the 0-120 min interval after each injection; ${ }^{*} p \leq 0.05,{ }^{* *} p \leq 0.01$ compared with the first injection of the Run. 

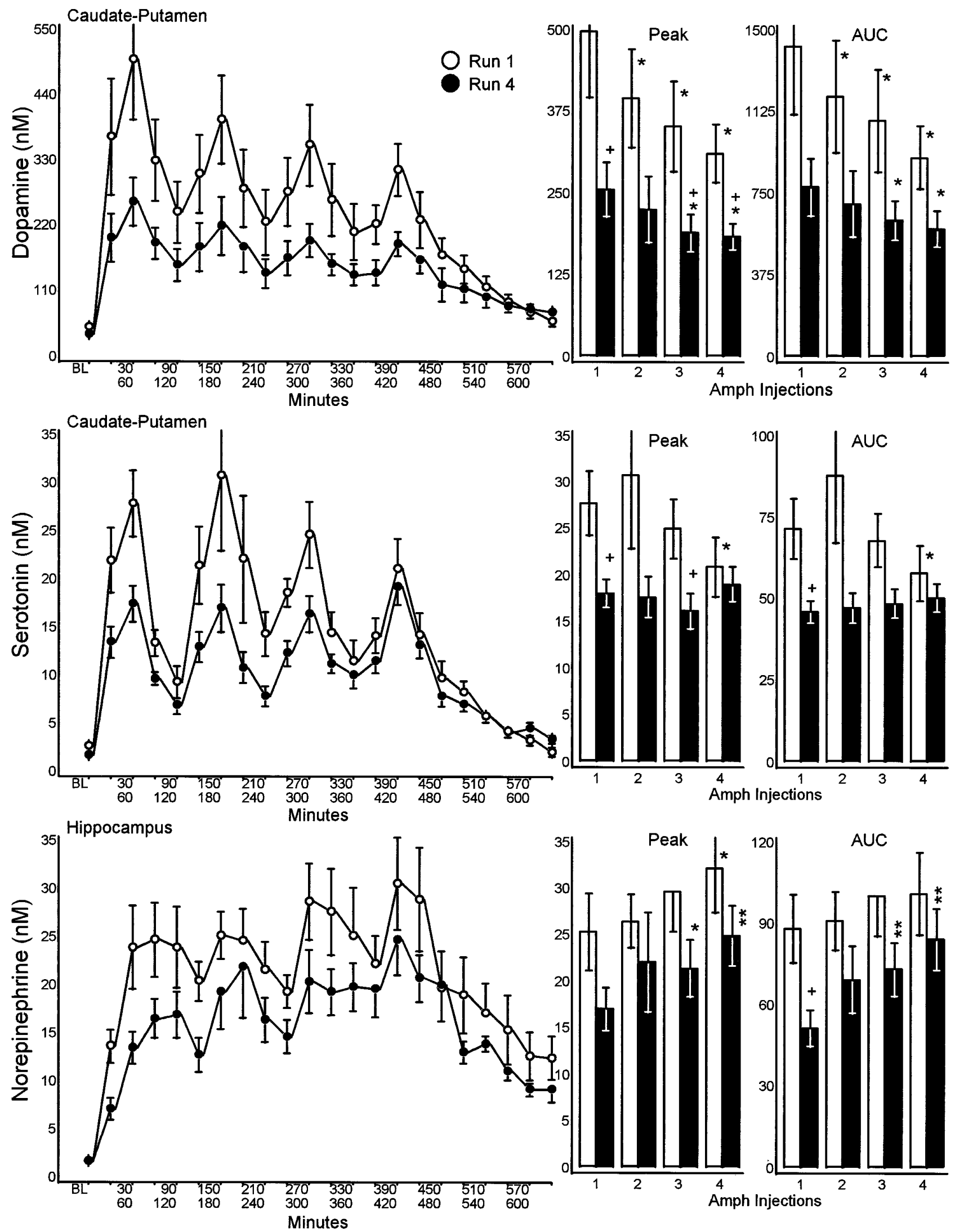

Figure 11. Extracellular neurotransmitter responses to multiple Runs of AMPH. Animals were pretreated with the Escalating Dose regimen of AMPH and then dialyzed during their first (Run 1) or fourth (Run 4) AMPH Run. $A U C$, Area under the curve for the 0-120 min interval after each injection; ${ }^{*} p \leq 0.05 ;{ }^{*} p \leq 0.01$ comparisons within each group to the first injection of the Run. $+p \leq 0.05$ comparisons between groups to the corresponding AMPH injection. 
stereotypy is an adaptive response that modulates high-intensity arousal (expressed in animals as agitated locomotion) and that this modulating mechanism is suppressed or impaired by the Escalating Dose-Run treatment. Therefore, rather than sensitization per se, a relatively unmodulated increase in arousal, which has been suggested as a critical factor in schizophrenic behavioral disorganization (Storms and Broen, 1969), may represent the critical change underlying the induction of stimulant psychosis.

With respect to stimulant-induced euphoria, acute tolerance or tachyphylaxis occurs, especially to the intense euphoria or "rush" within the course of each run (Fischman et al., 1985; Sato, 1986; Angrist, 1987, 1994b; Gawin and Ellinwood, 1988; Gawin and Khalsa, 1996). Some evidence also suggests a more chronic tolerance to euphoria that persists across repeated runs (for review, see Angrist, 1994b; Gawin and Khalsa, 1996). This progressive decrease in the pleasurable quality of the drug effect is believed to be a primary factor responsible for the escalation in dose and consequent compulsive drug use. Our results suggest that this effect may be attributable to the progressive attenuation of the DA and/or 5HT responses within and between runs and that an increase in dose might be expected to restore the transmitter response.

In contrast to the euphorigenic effects, the appearance of stimulant-induced paranoid psychosis is increasingly more likely with repeated, high-dose runs (for review, see Angrist, 1994b; Gawin and Khalsa, 1996). Our results suggest that the most prominent behavioral change that results with successive runs is a relative decrease in the amount of time the animals spend engaging in focused, continuous stereotypy and a corresponding increase in the time spent in what appears to be a highly agitated, hyperaroused state. As discussed previously, perseverative behavior may represent an adaptive response, especially in the context of excessive arousal or stress (see above for references). Therefore, the partial attenuation of this modulating mechanism during the course of repeated runs may be responsible for the pronounced psychomotor activation both in humans and in animals and to the induction of paranoid psychosis or psychotic mania in humans (Fibiger, 1991). The neurochemical evidence suggests that these behavioral changes may result from differential effects on mesolimbic and nigrostriatal DA systems, perhaps influenced by the $5 \mathrm{HT}$ and $\mathrm{NE}$ responses to this treatment.

It should be noted that one important assumption underlying the interpretation of our results, in the context of human stimulant abuse, is that the passive or noncontingent treatment procedures used in the present study produce effects qualitatively similar to those resulting from self-administration of stimulants. In this regard, some recent evidence suggests that comparable behavioral (Phillips and Di Ciano, 1996), neuroendocrine (Swerdlow et al., 1991), and brain neurochemical (Hurd et al., 1990; Swerdlow et al., 1991) effects are obtained using either contingent or noncontingent stimulant administration procedures. However, other reports (for example, Wilson et al., 1994) suggest potentially important differences after self versus passive drug administration. Therefore, additional investigation will be required to determine what, if any, actions of chronic stimulant abuse in humans are most accurately simulated by the use of contingent drug paradigms in experimental animals.

In conclusion, the results of these studies indicate that with the Escalating Dose-Run regimen, a behavioral profile emerges that differs qualitatively and quantitatively from the response produced by either repeated intermittent or continuous AMPH administration (Huberman et al., 1977; Ellison et al., 1978; Nielsen et al., 1980; Ellison, 1994). The altered responsiveness has features of both sensitization and tolerance, and its temporal pattern is characterized by a profound increase in the expression of locomotor activation relative to the period of continuous focused stereotypy. We suggest that this profile may reflect an enhanced level of arousal attributable, at least in part, to the attenuation of a coping mechanism, i.e., response perseveration. It is conceivable, therefore, that the shift in these two response components, perhaps mediated through a corresponding shift in the relative activation of the mesolimbic and nigrostriatal pathways, may also be implicated in the induction of stimulant psychosis.

\section{REFERENCES}

Angrist B (1987) Clinical effects of central nervous system stimulants: a selective update. In: Brain reward systems and abuse (Engel J, Oreland L, eds), pp 109-127. New York: Raven.

Angrist B (1994a) Psychosis-inducing effects of cocaine may show sensitization more than other effects. Neuropsychopharmacology 10:197S.

Angrist B (1994b) Amphetamine psychosis: clinical variations of the syndrome. In: Amphetamine and its analogs (Cho AK, Segal DS, eds), pp 387-414. San Diego: Academic.

Angrist B, Gershon S (1971) The phenomenology of experimentally induced amphetamine psychosis: preliminary observations. Biol Psychiatry 2:95-107.

Benveniste H, Hansen AJ, Ottosen NS (1989) Determination of brain interstitial concentrations by microdialysis. J Neurochem 52:1741-1750.

Berger SP, Hall S, Mickalian JD, Reid MS, Crawford CA, Delucchi K, Carr K (1996) Haloperidol antagonism of cue-elicited cocaine craving. Lancet 347:504-508.

Brady KT, Lydhard RB, Malcolm R, Ballenger JC (1991) Cocaineinduced paranoia. J Clin Psychiatry 52:509-512.

Breese GR, Cooper BR, Mueller RA (1974) Evidence for involvement of 5-hydroxytryptamine in the action of amphetamine. Br J Pharmacol 52:307-314.

Brodie BB, Shore PA (1957) A concept for a role of serotonin and norepinephrine as chemical mediators in the brain. Ann NY Acad Sci 66:631-642.

Castañeda E, Whishaw IQ, Robinson TE (1990) Changes in striatal dopamine neurotransmission assessed with microdialysis following recovery from a bilateral 6-OHDA lesion: variation as a function of lesion size. J Neurosci 10:1847-1854.

Church WH, Justice Jr JB (1987) Rapid sampling and determination of extracellular dopamine. Anal Chem 59:712-716.

Davis JM, Schlemmer Jr F (1980) The amphetamine psychosis. In: Amphetamines and related stimulants: chemical, biological, clinical and social aspects (Caldwell J, ed), pp 161-173. Boca Raton, FL: CRC.

Ellison G (1994) Stimulant-induced psychosis: the dopamine theory of schizophrenia, and the habenula. Brain Res Rev 19:223-239.

Ellison G, Eison MS (1983) Continuous amphetamine intoxication: an animal model of the acute psychotic episode. Psychol Med 13:751-761.

Ellison G, Eison MS, Huberman HS, Daniel F (1978) Long-term changes in dopaminergic innervation of caudate nucleus after continuous amphetamine administration. Science 276-278.

Fibiger HC (1991) The dopamine hypotheses of schizophrenia and mood disorders: contradictions and speculations. In: The mesolimbic dopamine system: from motivation to action (Willner P, Scheel-Kruger J, eds), pp 616-637. London: Wiley.

Fischman MW, Schuster CR (1974) Tolerance development to chronic methamphetamine intoxication in the rhesus monkey. Pharmacol Biochem Behav 2:503-508.

Fischman MW, Schuster CR (1977) Long-term behavioral changes in the rhesus monkey after multiple daily injections of d-methylamphetamine. J Pharmacol Exp Ther 201:593-605.

Fischman MW, Schuster C, Javaid J, Hatano Y, Davis J (1985) Acute tolerance development to the cardiovascular and subjective effects of cocaine. J Pharmacol Exp Ther 235:677-682.

Florin SM, Kuczenski R, Segal DS (1995) Effects of reserpine on extracellular caudate dopamine and hippocampus norepinephrine responses to amphetamine and cocaine: mechanistic and behavioral considerations. J Pharmacol Exp Ther 274:231-241.

Gawin FH (1991) Cocaine addiction: psychology and neurophysiology. Science 251:1580-1586. 
Gawin FH, Ellinwood EJ (1988) Cocaine and other stimulants. Actions, abuse, and treatment. N Engl J Med 318:1173-1182.

Gawin FH, Khalsa ME (1996) Sensitization and "street" stimulant addiction. In: Neurotoxicity and neuropathology associated with stimulant abuse, NIDA Monograph 163, pp 224-250. Washington, DC: US GPO.

Geyer MA, Puerto A, Menkes DB, Segal DS, Mandell AJ (1976) Behavioral studies following lesions of the mesolimbic and mesostriatal serotonergic pathways. Brain Res 106:257-270.

Griffith JD, Cavanaugh J, Held J, Oates JA (1972) Dextroamphetamine. Arch Gen Psychiatry 26:97-100.

Hyman SE (1996) Addiction to cocaine and amphetamine. Neuron 16:901-904.

Hyman SE, Nestler EJ (1996) Initiation and adaptation: a paradigm for understanding psychotropic drug action. Am J Psychiatry 153:151-162.

Huberman HS, Eison MS, Bryan KS, Ellison G (1977) A slow release silicone pellet for chronic amphetamine administration. Eur J Pharmacol 45:237-242.

Hurd YL, Weiss F, Koob G, Ungerstedt U (1990) The influence of cocaine self-administration on in vivo dopamine and acetylcholine neurotransmission in rat caudate-putamen. Neurosci Lett 109:227-233.

Jacobs BL, Wise WD, Taylor KM (1975) Is there a catecholamineserotonin interaction in the control of locomotor activity? Neuropharmacology 14:501-506.

Kalivas PW, Duffy P (1993) Time course of extracellular dopamine and behavioral sensitization to cocaine. I. Dopamine axon terminals. J Neurosci 13:266-275

Kalivas PW, Sorg BA, Hooks MS (1993) The pharmacology and neural circuitry of sensitization to psychostimulants. Behav Pharmacol 4:315-334.

Kilbey MM, Ellinwood Jr EH (1977) Chronic administration of stimulant drugs: response modification. In: Cocaine and other stimulants (Ellinwood Jr EH, Kilbey MM, eds), pp 409-425. New York: Plenum.

Kleber HD (1995) Pharmacotherapy, current and potential, for the treatment of cocaine dependence. Clin Neuropharmacol 18:S96-S109.

Kramer JC (1972) Introduction to amphetamine abuse. In: Current concepts on amphetamine abuse (Ellinwood Jr EH, Cohen S, eds), pp 177-184. Washington, DC: US GPO.

Kuczenski R, Segal DS (1988) Psychomotor stimulant-induced sensitization: behavioral and neurochemical correlates. In: Sensitization in the nervous system (Kalivas P, Barnes T, eds), pp 175-205. Caldwell, NJ: Telford.

Kuczenski R, Segal DS (1989) Concomitant characterization of behavioral and striatal neurotransmitter response to amphetamine using in vivo microdialysis. J Neurosci 9:2051-2065.

Kuczenski R, Segal DS (1990) In vivo measures of monoamines during amphetamine-induced behaviors in rats. Prog Neuropsychopharmacol Biol Psychiatry 14(Suppl):S37-S50.

Kuczenski R, Segal DS, Aizenstein ML (1991) Amphetamine, fencamfamine, and cocaine: Relationships between locomotor and stereotypy response profiles and caudate and nucleus accumbens dopamine dynamics. J Neurosci 11:2703-2712.

LeDuc P, Mittleman G (1995) Schizophrenia and psychostimulant abuse. A review and re-analysis of clinical evidence. Psychopharmacology 121:407-427.

Lieberman J, Kinon BJ, Loebel AD (1990) Dopaminergic mechanisms in idiopathic and drug-induced psychoses. Schizophr Bull 16:97-110.

Mabry PD, Campbell BA (1973) Serotonergic inhibition of catecholamine-induced behavioral arousal. Brain Res 49:381-391.

Mason GJ (1991) Stereotypies: a critical review. Anim Behav 41:1015-1037.

Melega WP, Williams AE, Schmitz DA, DiStefano EW, Cho AK (1995) Pharmacokinetic and pharmacodynamic analysis of the actions of D-amphetamine and D-methamphetamine on the dopamine terminal. J Pharmacol Exp Ther 274:90-96.

Mittleman G, Jones GH, Robbins TW (1991) Sensitization of amphetamine-stereotypy reduces plasma corticosterone: implications for stereotypy as a coping response. Behav Neural Biol 56:170-182.

Neill DB, Grant LD, Grossman SP (1972) Selective potentiation of locomotor effects of amphetamine by midbrain raphe lesions. Physiol Behav 9:655-657.

Nestler EJ (1994) Molecular neurobiology of drug addiction. Neuropsychopharmacology 11:77-87.

Nielsen EN, Lee TH, Ellison G (1980) Following several days of continuous administration, d-amphetamine acquires hallucinogen-like properties. Psychopharmacology 68:197-200.
Paulson PE, Robinson TE (1995) Amphetamine-induced timedependent sensitization of dopamine neurotransmission in the dorsal and ventral striatum: a microdialysis study in behaving rats. Synapse 19:56-65.

Paulson PE, Robinson TE (1996) Regional differences in the effects of amphetamine withdrawal on dopamine dynamics in the striatum: analysis of circadian patterns using automated on-line microdialysis. Neuropsychopharmacology 14:325-337.

Paulson PE, Camp DM, Robinson TE (1991) Time course of transient behavioral depression and persistent behavioral sensitization in relation to regional brain monoamine concentrations during amphetamine withdrawal in rats. Psychopharmacology 103:480-492.

Phillips AG, Di Ciano P (1996) Behavioral sensitization is induced by intravenous self-administration of cocaine by rats. Psychopharmacology 124:279-281.

Post RM, Kopanda RT (1976) Cocaine, kindling, and psychosis. Am J Psychiatry 133:627-634.

Rebec GV, Segal DS (1980) Apparent tolerance to some aspects of amphetamine stereotypy with long-term treatment. Pharmacol Biochem Behav 13:793-799.

Robinson TE, Becker JB (1986) Enduring changes in brain and behavior produced by chronic amphetamine administration: a review and evaluation of animal models of amphetamine psychosis. Brain Res Rev 11:157-198

Robinson TE, Jurson PA, Bennett JA, Bentgen KM (1988) Persistent sensitization of dopamine neurotransmission in ventral striatum (nucleus accumbens) produced by prior experience with $(+)$-amphetamine: a microdialysis study in freely moving rats. Brain Res 462:211-222.

Rylander G (1969) Clinical and medico-criminological aspects of addiction to central stimulating drugs. In: Abuse of central stimulants (Sjoqvist F, Tottie M, eds), pp 11-15. Stockholm: Almqvist W Forlag AB.

Rylander G (1980) Clinical and medico-criminological aspects of addiction to central stimulating drugs. In: Use and abuse of amphetamine and its substitutes (Spotts JV, Spotts CA, eds), pp 299-300. Washington, DC: US GPO.

Satel SL, Southwick SM, Gawin FH (1991) Clinical features of cocaineinduced paranoia. Am J Psychiatry 148:495-498.

Sato M (1986) Acute exacerbation of methamphetamine psychosis and lasting dopaminergic supersensitivity—a clinical survey. Psychopharmacol Bull 22:751-756.

Schiorring E (1977) Changes in individual and social behavior induced by amphetamine and related compounds in monkeys and man. In: Cocaine and other stimulants (Ellinwood Jr EH, Kilbey MM, eds), pp 481-522. New York: Raven.

Schmidt CJ, Gehlert DR, Peat MA, Sonsalla PK, Hanson GR, Wamsley JK, Gibb JW (1985a) Studies on the mechanism of tolerance to methamphetamine. Brain Res 343:305-313.

Schmidt CJ, Sonsalla PK, Hanson GR, Peat MA, Gibb JW (1985b) Methamphetamine-induced depression of monoamine synthesis in the rat: development of tolerance. J Neurochem 44:852-855.

Schuster CR, Fischman MW (1975) Amphetamine toxicity: behavioral and neuropathological indexes. Fed Proc 34:1845-1851.

Segal DS (1975a) Behavioral characterization of d- and l-amphetamine: neurochemical implications. Science 190:475-477.

Segal DS (1975b) Behavioral and neurochemical correlates of repeated d-amphetamine administration. In: Advances in biochemical psychopharmacology (Mandell AJ, ed), pp 247-266. New York: Raven.

Segal DS (1976) Differential effects of para-chlorophenylalanine on amphetamine-induced locomotion and stereotypy. Brain Res 116:267-276.

Segal DS (1977) Differential effects of serotonin depletion on amphetamine-induced locomotion and stereotypy. In: Cocaine and other stimulants (Ellinwood Jr EH, Kilbey MM, eds), pp 431-443. New York: Raven.

Segal DS, Geyer MA (1985) Animal models of psychopathology. In: Psychiatry (Cavenar Jr JO, ed). Philadelphia: Lippincott.

Segal DS, Janowsky DS (1978) Psychostimulant-induced behavioral effects: possible models of schizophrenia. In: Psychopharmacology: a generation of progress (Lipton MA, DiMascio A, Killam KF, eds), pp 1113-1124. New York: Raven.

Segal DS, Kuczenski R (1987) Individual differences in responsiveness to single and repeated amphetamine administration: behavioral characteristics and neurochemical correlates. J Pharmacol Exp Ther 242:917-926. 
Segal DS, Kuczenski R (1992a) In vivo microdialysis reveals a diminished amphetamine-induced dopamine response corresponding to behavioral sensitization produced by repeated amphetamine pretreatment. Brain Res 571:330-337.

Segal DS, Kuczenski R (1992b) Repeated cocaine administration induces behavioral sensitization and corresponding decreased extracellular dopamine responses in caudate and accumbens. Brain Res 577:351-355.

Segal DS, Kuczenski R (1994) Behavioral pharmacology of amphetamine. In: Amphetamine and its analogs (Cho AK, Segal DS, eds), pp 115-150. San Diego: Academic.

Segal DS, Mandell AJ (1974) Long-term administration of d-amphetamine: progressive augmentation of motor activity and stereotypy. Pharmacol Biochem Behav 2:249-255.

Segal DS, Schuckit MA (1983) Animal models of stimulant-induced psychosis. In: Stimulants: neurochemical, behavioral and clinical perspectives (Creese I, ed), pp 131-167. New York: Raven.

Segal DS, Weinberger S, Cahill J, McCunney S (1980) Multiple daily amphetamine administration: behavioral and neurochemical alterations. Science 207:904-907.

Segal DS, Geyer MA, Schuckit MA (1981) Stimulant-induced psychosis: an evaluation of animals models. In: Essays in neurochemistry and neuropharmacology (Youdim MBH, Lovenberg W, Sharman DF, Lagnado JR, eds), pp 95-129. Sussex, United Kingdom: Wiley.

Stahle L, Segersvärd S, Ungerstedt U (1991) A comparison between three methods for estimation of extracellular concentrations of exogenous and endogenous compounds by microdialysis. J Pharmacol Methods 25:41-52.

Storms LH, Broen WE (1969) A theory of schizophrenic behavioral disorganization. Arch Gen Psychiatry 20:129-144.

Swerdlow NR, Hauger R, Irwin M, Koob GF, Britton KT, Pulverenti L (1991) Endocrine, immune, and neurochemical changes in rats during withdrawal from chronic amphetamine intoxication. Neuropsychopharmacology 5:23-31.

Swonger AK, Rech RH (1972) Serotonergic and cholinergic involvement in habituation of activity and spontaneous alterations of rats in a $\mathrm{Y}$ maze. J Comp Physiol Psychol 81:509-522.

Unterwald EM, Ho A, Rubenfeld JM, Kreek MJ (1994) Time course of the development of behavioral sensitization and dopamine receptor up-regulation during binge cocaine administration. J Pharmacol Exp Ther 270:1387-1396.

Wages SA, Church WH, Justice Jr JB (1986) Sampling considerations for on-line microbore liquid chromatography of brain dialysis. Anal Biochem 58:1649-1656.

Whishaw IQ, Fiorino D, Mittleman G, Castañeda E (1992) Do forebrain structures compete for behavioral expression? Evidence from amphetamine-induced behavior, microdialysis, and caudateaccumbens lesions in medial frontal cortex damaged rats. Brain Res 576:1-11.

Wilson JM, Nobrega JN, Corigall WA, Coen KM, Shannak K, Kish SJ (1994) Amygdala dopamine levels are markedly elevated after self- but not passive-administration of cocaine. Brain Res 668:39-45.

Wilson JM, Kalasinksy KS, Levey AI, Bergeron C, Reiber G, Anthony RM, Schmunk GA, Shannak K, Haycock JW, Kish SJ (1996) Striatal dopamine nerve terminal markers in human, chronic methamphetamine users. Nature Med 2:699-703.

Wolf ME, White FJ, Hu X-T (1993) Behavioral sensitization to MK801 (dizocilpine): neurochemical and electrophysiological correlates in the mesoaccumbens dopamine system. Behav Pharmacol 4:429-442.

Wolf ME, White FJ, Hu X-T (1994) MK-801 prevents alterations in the mesoaccumbens dopamine system associated with behavioral sensitization to amphetamine. J Neurosci 14:1735-1745. 